Textos 



\title{
Populações tradicionais e a Convenção da Diversidade Biológica*
}

\author{
MANUELA CARNEIRO DA CUNHA
}

Q

UERO AGRADECER ao Instituto de Estudos Avançados, e em particular ao seu diretor, Alfredo Bosi, o honroso convite para proferir a Conferência do Mês. Vou falar aqui de questões muito atuais, mas de certa complexidade, e por não saber o quanto os que me escutam estão já familiarizados com o assunto, tentarei começar com as informações mais básicas.

\section{A Convenção da Diversidade Biológica e suas repercussões no Brasil}

São três os objetivos apregoados da Convenção da Diversidade Biológica $(\mathrm{CDB})$ :

- a conservação da diversidade biológica;

- o uso sustentável de suas partes constitutivas;

- a repartição justa e eqüitativa dos benefícios que advêm do uso dos recursos genéticos.

A CDB é um instrumento de direito internacional, acordado e aberto a adesões durante a reunião das Nações Unidas realizada no Rio de Janeiro em junho de 1992. Até o final de 1997, 187 países já haviam aderido e, na sua imensa maioria (169), ratificado, também, as disposições da Convenção. No Brasil, essa ratificação se deu através do Congresso Nacional, em maio de 1994. Com a ratificação, a Convenção passou a ter valor de lei interna ao país. Sem regulamentação, no entanto, a Convenção não se tornou operatória. Nesse sentido, a senadora Marina Silva (PT/Acre) apresentou, em 1995, um projeto de lei de Acesso ao Patrimônio Genético e ao

* Conferência do Mês do Instituto de Estudos Avançados da USP feita pela autora em 17 de junho de 1998. 
conhecimento associado (Projeto de Lei no Senado 306/95), discutindo-o amplamente com representantes da sociedade civil em vários pontos do país. Um substitutivo foi apresentado pelo relator, senador Osmar Dias (PSDB/Paraná), e aprovado em fins de 1997, na Comissão de Assuntos Sociais do Senado. Consta que já foi aprovado também na Comissão de Educação do Senado. Foi apresentado na Câmara, em fins de maio de 1998, um novo projeto de regulamentação de autoria de Jacques Wagner (PT/Bahia). Finalmente, o governo formou um Grupo Interministerial de Acesso aos Recursos Genéticos, que deve resultar brevemente em uma proposta de lei na Câmara.

\section{O público e o privado}

Da Convenção da Diversidade Biológica quero destacar alguns aspectos.

Até 1992 havia uma curiosa dualidade com relação aos direitos de propriedade intelectual. Por um lado, considerava-se que recursos genéticos e conhecimentos tradicionais eram patrimônio da humanidade: por conterem esperança da descoberta de remédios para a cura do câncer, da aids e de outros flagelos; por permitirem renovação de estoque genético e, portanto, resistência de cultivares às pragas que os atacam, os recursos genéticos e conhecimentos tradicionais deveriam ser de acesso livre. $\mathrm{O}$ paradoxo é que, na outra ponta do processo, no mundo da biotecnologia, ao contrário, tudo era patenteado e os remédios e sementes propriedade estritamente privada, embora seus benefícios para o conjunto da humanidade também fossem incontestáveis. Fundamentando o patenteamento de remédios e sementes estava a idéia básica de que a privatização das descobertas estimula a inovação. Essa diferença de tratamento coincidia, não por acaso, com a divisão Norte-Sul. Os países em desenvolvimento detinham, em 1975, apenas 1,7\% das patentes mundiais (Unctad/Wipo, 1975 apud Grain). No entanto, esses mesmos países eram responsáveis pela esmagadora maioria dos recursos genéticos mundiais. Dos 12 centros de megadiversidade no mundo, 11 encontram-se no hemisfério Sul. As três classes de agentes terapêuticos mais ativos contra o HIV identificados até agora pelo Instituto Nacional do Câncer dos Estados Unidos provêm de plantas, respectivamente, da República dos Camarões, da Austrália e da Malásia (Mays et al., 1996:262). Ou seja, a tecnologia é do Norte, o germoplasma do Sul. E a tecnologia se pagava, enquanto o germoplasma era de graça.

À primeira vista, de duas uma: ou em ambas as pontas do processo, nos recursos genéticos, nos conhecimentos tradicionais associados e tam- 
bém nos produtos resultantes de processos biotecnológicos, tudo se torna de livre acesso, patrimônio comum da humanidade, ou, então, nas duas pontas, tudo deveria ser privatizado e recursos genéticos e conhecimentos serem protegidos na mesma medida em que os produtos da biotecnologia o são (Cunningham, 1993). Veremos que nenhum dos termos da alternativa é tão simples quanto parece.

Durante a década de 70 e início dos anos 80, a resistência a uma privatização generalizada desembocou na primeira solução. Os recursos deveriam ser de livre acesso nas duas pontas, foi o que declarou em 1983 a Resolução Internacional sobre Recursos Fitogenéticos da FAO (Organização de Alimento e Agricultura). Quase 10 anos mais tarde, a saída dada pela CDB foi a segunda: privatizar nas duas pontas e trocar tecnologia por acesso a recursos genéticos. Recursos genéticos não seriam patrimônio da humanidade e sim objeto da soberania dos países em que se localizassem. E a compensação pelo acesso a eles seria essencialmente a transferência de tecnologia.

\section{Populações locais e Estados nacionais}

Subsistiram, no entanto, problemas de vários tipos, de que falaremos a seguir. Mencionaremos aqui apenas um deles, o da transmissão dos benefícios aos grupos locais. Afinal, quem ocupa as áreas de maior riqueza genética, não por acaso, mas porque são produtores de diversidade? E quem são os produtores do conhecimento associado? São precisamente populações tradicionais, e usarei por enquanto esta expressão em sua acepção mais vaga e abrangente. Estas populações, com toda a justiça, querem participar das decisões relativas a seus territórios e usufruir eqüitativamente, seguindo os próprios termos da CDB, de parcela dos benefícios. Ora, nem sempre os Estados nacionais thes dão a devida consideração, nem na consideração de sua vontade, nem na repartição dos benefícios.

A CDB contém dois dispositivos importantes a este respeito:

- $O$ art. 8(j) solicita aos Estados-membros da convenção que "de acordo com sua legislação nacional, respeitem, preservem e mantenham o conhecimento, as inovações e as práticas das comunidades indígenas e locais que incorporam estilos de vida tradicionais relevantes para a conservação e o uso sustentado da diversidade biológica e que promovam sua aplicação mais ampla com o assentimento e envolvimento dos detentores desses conhecimentos, inovações e práticas e encoragem o compartilhar eqüitativo dos benefícios resultantes da utilização desses conhecimentos, inovações e práticas”. 
- O artigo 15, que garante aos Estados a soberania sobre seus recursos genéticos e trata dos modos de lhes facilitar o acesso, estipula, entre outras coisas, a necessidade de consentimento prévio fundamentado. Cabe aos Estados-membros da Convenção darem esse consentimento, e a CDB não menciona os mecanismos internos para obtê-lo. Pelo art. 8(j), não há dúvida de que o assentimento prévio e informado das comunidades indígenas e locais deve ser obtido com relação aos conbecimentos, inovações e práticas.

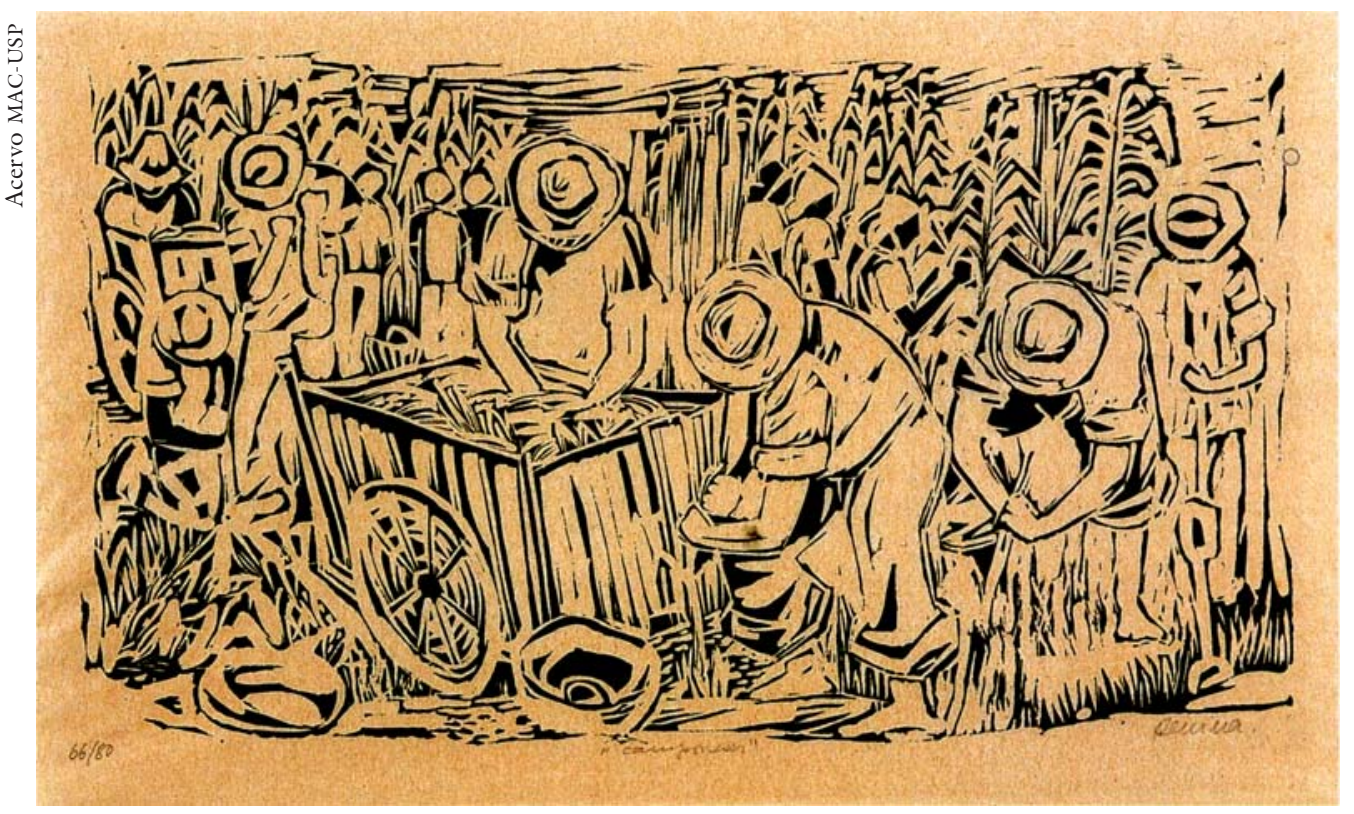

Renina Katz (Rio de Janeiro, RJ, 1925). Camponeses, 1948/56.

Xilogravura a cores s/papel, $41.1 \times 31.8$, col. MAC-USP.

Mas no que tange aos recursos genéticos a serem obtidos em terras indígenas ou em terras de grupos tradicionais, a CDB é muda. Este é um dos pontos controversos na atual discussão da regulamentação da CDB no Brasil. Há neste ponto um argumento substantivo e um argumento legal.

Substantivamente, a CDB tem por objetivo, lembramos, a conservação da diversidade biológica, o uso sustentável de suas partes constitutivas e a repartição justa e eqüitativa dos benefícios que advêm do uso dos recursos genéticos. Ora, se se trata de incentivar o uso sustentável e a conservação da diversidade, além de negociar com os governos, deve-se evidentemente tratar com as populações que habitam as áreas detentoras de recursos genéticos e que são suas guardiães efetivas. Quando mais não fora, e dentro de uma estrita perspectiva economicista, seria necessário convencer tanto os governos quanto as populações locais das vantagens da conserva- 
ção e do uso sustentável sobre outras opções possíveis - criação de gado, extração de madeira etc. - mas destrutivas da biodiversidade. Ou seja, levar em conta o que os economistas chamam de custo de oportunidade.

Quanto ao argumento legal, pelo menos no que diz respeito às comunidades indígenas, a Constituição Federal é clara. O artigo 231, parágrafo 3 , reconhece seus direitos ao usufruto exclusivo das riquezas do solo, dos rios e dos lagos em suas terras. Abrem-se duas exceções que exigem aprovação do Congresso Nacional, para o aproveitamento dos recursos hídricos e riquezas do subsolo. Os recursos genéticos não se encontram portanto entre as exceções eventuais ao usufruto exclusivo das riquezas. Segue-se que fazem parte delas e portanto que o consentimento fundamentado das comunidades indígenas é condição sine qua non para o acesso aos recursos genéticos (1).

Condição necessária, portanto, mas não suficiente. Este é um ponto que eu queria enfatizar, pois, se por um lado, não se pode prescindir do assentimento e da participação das populações locais, por outro não se pode solapar a autoridade dos Estados sobre o acesso aos recursos genéticos. Ora, acho que é isso que está acontecendo em vários países da América Latina. Explico-me.

Embora os EUA não tenham ratificado a $\mathrm{CDB}$, na prática estão implementando, mediante contratos, suas idéias básicas de troca de germoplasma por transferência de tecnologia. Assim procedendo, estão estabelecendo precedentes de interpretação em uma área que carece ainda de definições. Esses contratos estão se tornando mais progressistas com o tempo. Basta comparar iniciativas mais antigas, como a do Instituto Nacional do Câncer (NCI) que, desde 1955 pesquisa, em produtos naturais, agentes anticâncer e, mais recentemente, antiaids, com o programa ICBG (International Cooperative Biodiversity Groups - Grupos de Biodiversidade de Cooperação Internacional), iniciado experimentalmente em 1993 por iniciativa do NIH (National Institute of Health), da NSF (National Science Foundation) e USAID (U.S. Agency for International Development).

O NCI, embora reconheça a importância do conhecimento indígena e tradicional, e coloque entre as obrigações dos Estados nacionais a de fornecer informações existentes localmente sobre os recursos genéticos coletados, limita-se a assegurar (no protocolo de acesso que elaborou) que pedirá à comunidade ou ao especialista local a autorização para publicar seu conhecimento e mencionará a autoria dos conhecimentos locais. Nada está previsto quanto à sua retribuição direta, a não ser uma preferência por coletar material no lugar de origem da informação. O Instituto Nacional 
do Câncer limita-se a prometer esforços sinceros no sentido de transferir tecnologia relativa ao material genético, desde que as patentes estejam salvaguardadas (Mays et al., 1996). Estas precauções são aliás indicativas da preeminência da questão das patentes sobre a questão da diversidade biológica e das razões que impedem os EUA de ratificar a CDB.

Muito diferente é o programa ICBG (Grupos de Biodiversidade de Cooperação Internacional), iniciado em 1993 com cinco projetos. O padrão geral desses projetos associa universidades ou institutos de pesquisa norte-americanos aos do assim chamado país provedor, uma indústria farmacêutica multinacional, comunidades ou organizações locais e ONGs que trabalham na região (Rosenthal, 1996). Mas os contratos específicos estão na realidade inovando, e prevêem, entre outras coisas, benefícios e remuneração, com variações em cada caso, para organizações locais, tanto governamentais quanto não-governamentais.

A escolha dessas organizações é, em princípio, baseada no seu papel efetivo na conservação dos recursos genéticos. Os pagamentos são em geral uma combinação de royalties sobre os eventuais produtos e pagamentos imediatos no momento da coleta. Essa tomada em consideração das demandas e das contribuições das populações locais é salutar e deveria servir de exemplo: é usual que se depreciem os aportes das populações locais quando esses contratos são feitos unicamente entre parceiros de um mesmo país.

Mas há o reverso da medalha: parte da inovação dos contratos do ICBG é que os Estados nacionais passam a opinar pouco, em uma lógica que é consistente com o neoliberalismo reinante. Uma das conseqüências é que interesses nacionais não têm como se afirmar. Por exemplo: o jogo do mercado por si só não permite que se estabeleçam prioridades para a pesquisa de doenças importantes para o país, mas não-necessariamente importantes para as companhias farmacêuticas, como, entre outras, a malária e a doença de Chagas. Outras conseqüências são que os termos das negociações e a participação nos benefícios passam a depender fortemente do grau de organização e mobilização dos grupos locais, o que pode significar, no caso de grupos mais vulneráveis, uma venda a vil preço de seus recursos e conhecimentos ou a perda para o país da oportunidade de valorizar seus próprios recursos genéticos e conhecimentos (2). Caberia ao Estado estabelecer os parâmetros mínimos para essas negociações, aplicáveis a instituições nacionais e estrangeiras.

Em suma, queria enfatizar aqui que nem o Estado deve excluir ou desrespeitar sociedades indígenas e tradicionais no processo de decisão e na repartição dos benefícios, nem tampouco a exploração de recursos ge- 
néticos e conhecimentos associados deve esquecer o bem comum, a coisa pública que o Estado deveria garantir. No nosso país, a lamentável tradição é de se excluírem as sociedades tradicionais, mas a reação a esse estado de coisas não deve nos fazer perder de vista a coisa pública. A aliança fundamental a ser buscada é a das prioridades ambientais do país com as prioridades das comunidades locais e as prioridades nacionais.

\section{CDB versus TRIPS}

A CDB foi decidida no foro das Nações Unidas e encontrou uma série de restrições dos EUA, sobretudo referentes à transferência de tecnologia. Os EUA preferiram mudar as discussões para um foro que lhes fosse mais favorável, o do GATT (General Agreement on Trade and Tariffs), substituído em 1995 pelo WTO (OMC - Organização Mundial de Comércio). Substituído, mas também fortalecido: no final da chamada Rodada do Uruguai, conseguiram vincular sanções comerciais à exigência de normas mínimas de proteção à propriedade intelectual. Ou seja, patentes deveriam ser respeitadas mundialmente. Não é evidentemente por acaso: vimos que a esmagadora maioria das patentes são detidas pelos países desenvolvidos. Os EUA reclamavam em 1994 que só em produtos farmacêuticos perdiam, por ano, US\$ 2 bilhões e meio de royalties que não eram pagos. Essa pressão resultou nos chamados TRIPS (Trade-Related Intellectual Property Rights - Direitos de Propriedade Intelectual relacionados ao Comércio) que entraram em vigor a $1^{\circ}$ de janeiro de 1995 para serem implementados, seja desde 1996 para os países desenvolvidos, seja após um período de transição que varia: $1^{\circ}$ de janeiro de 2000, ou $1^{\circ}$ de janeiro de 2005 , no caso de países em desenvolvimento e menos desenvolvidos, respectivamente. No Brasil, essa transição, que deveria ser concluída em 2000, já está quase completa: resultou na lei de Marcas e Patentes (9.279) de maio de 1996 (na base da qual o INPI concedeu a 16.6 .98 as primeiras oito patentes pipeline), na lei de Proteção de Cultivares de 25 de abril de 1997 e, mais recentemente, na nova lei sobre direitos autorais (9.610 de 19.2.98).

As normas de que trata o TRIPS implicam na internacionalização dos direitos de propriedade intelectual, qualquer que tenha sido o seu lugar de origem. Uma patente, por exemplo, que é uma das formas de propriedade intelectual, teria de ser respeitada por qualquer país membro da Organização Mundial do Coméercio. No entanto, existem algumas ressalvas: os países membros podem excluir patentes por razões de saúde pública, de efeitos no meio ambiente e, de forma mais geral, por razões de ordem pública e moralidade (art. 27.2). Podem também tornar não-patenteáveis métodos de diagnóstico, terapêuticos e cirúrgicos, para tratamento de se- 
res humanos e animais (art. 27.3 a). E, por fim (art. 27.3 b), embora não possam excluir micro-organismos ou seres vivos produzidos por outros meios, por exemplo, por modificação genética, podem excluir patentes sobre seres vivos, desde que sejam seres obtidos por processos essencialmente biológicos. Esta exceção, relativa a plantas e animais biologicamente produzidos, contém, por sua vez, uma ressalva com relação a plantas. Os países que não quiserem patentear variedades de plantas devem adotar um sistema sui generis, mas eficaz, para proteger os direitos intelectuais sobre tais variedades. Na época da redação do TRIPS, os Estados Unidos e a União Européia tinham legislações heterogêneas com relação aos sistemas de proteção de variedades de plantas. A ressalva foi um compromisso considerado provisório e sua origem explica que a ressalva deve conter uma cláusula embutida de revisão, marcada para 1999. Essas acomodações sucessivas traduzem-se na estranha redação do artigo 27.3 b. O que a revisão prevista significa é uma nova queda de braço entre os interesses do Norte e os do Sul, entre uma extensão do sistema de patentes para passar a cobrir seres vivos e uma resistência a essa extensão aliada ao reconhecimento do conhecimento tradicional. Ganhando a posição dos EUA, abole-se o artigo 27.3 b; ganhando a posição do Sul, abole-se a ressalva a esse artigo e acrescentam-se garantias aos direitos intelectuais coletivos das populações tradicionais de que falarei mais adiante. Em grande medida, o resultado vai depender de uma desejável coalizão entre países do Sul.

\section{A defesa dos bens públicos}

Mencionei anteriormente uma alternativa que parecia simples e de bom senso. Ou o conhecimento é livre nas duas pontas do processo ou é privatizado igualmente. O problema não é tão simples, porém, pois a alternativa é colocada, reparem, nos termos de um mundo em que predomina o privado. Patentes no estilo norte-americano, que o TRIPS procura generalizar, assentam-se em um tipo ideal, o inventor solitário que consegue descobrir algo novo, não-óbvio e útil. Esse tipo ideal, diga-se de passagem, é obsoleto até para os EUA. Seja como for, para estimular a invenção e fazer avançar a tecnologia, deve-se recompensar esse herói inovador, durante um certo tempo, com o usufruto exclusivo dos benefícios de sua obra. Ou seja, estamos nos movendo em um imaginário individualista, economicista e desenvolvimentista (3).

O que acontece se nos permitirmos subverter os termos em que nos é dada a escolha (Escobar, 1994)? O que acontece se se colocar a livre circulação de idéias e conhecimentos como um valor básico (como se faz na Universidade) superior à sua apropriação privada? O que acontece se se 
afirmar que os conhecimentos tradicionais têm um valor, sim, na cadeia de produção de mercadorias, mas que não podem ser tratados como mercadorias? Se se afirmar, como fez a FAO (Organização de Alimento e Agricultura) ao proclamar os direitos dos agricultores, que eles devem ser recompensados pela sua contribuição ao desenvolvimento de variedades úteis? Que eles não devem pagar royalties por sementes? Em suma, se se defendem os bens públicos? Essa havia sido, lembremos, a postura inicial da FAO em 1983, que desencadeou o que Kloppenburg \& Kleinman (1987) chamaram de "guerra das sementes" travada entre a agroindústria produtora de sementes e os países que defendiam os direitos de seus agricul-

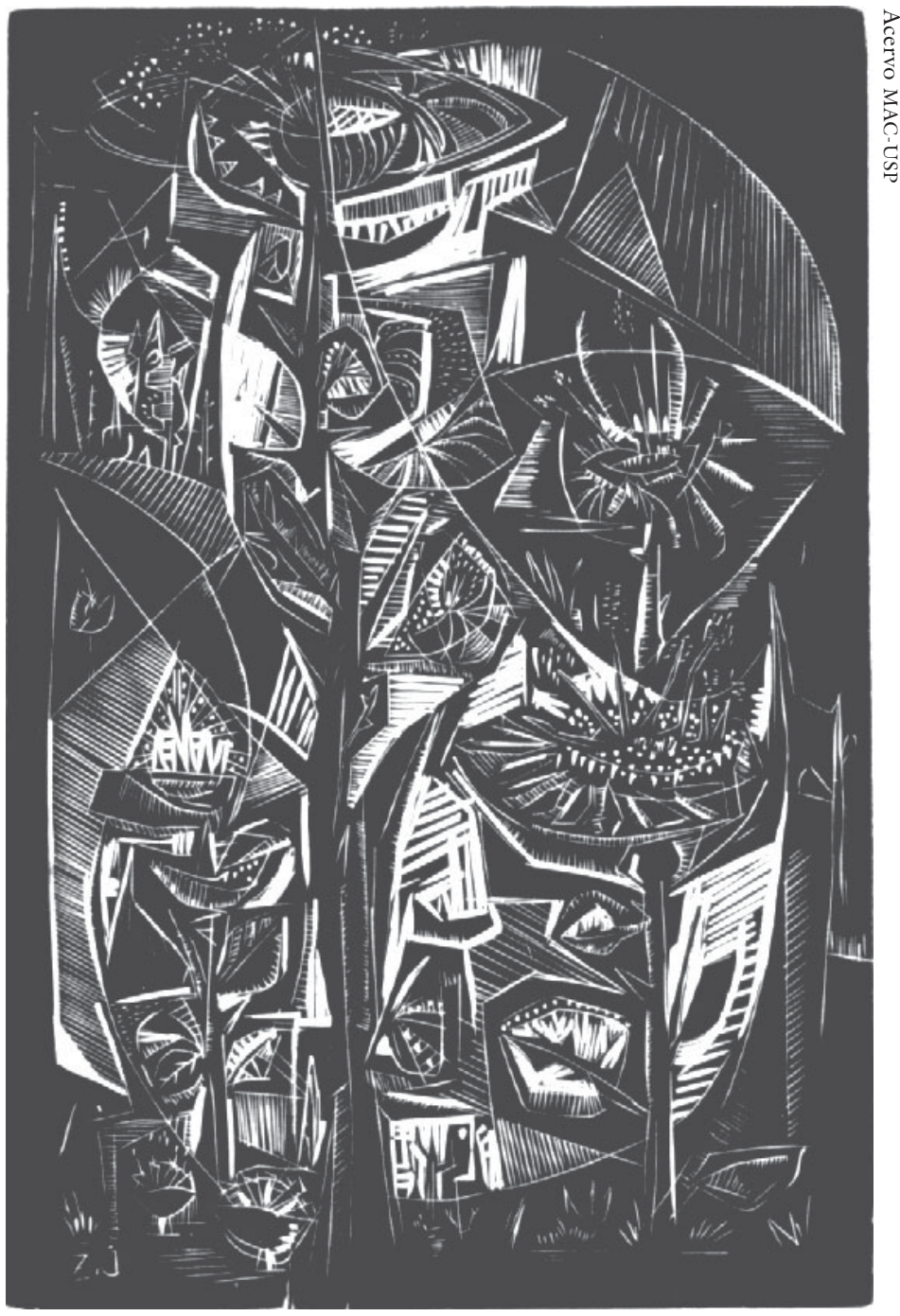

Zalazar Johnson (Argentina, 1933).

Plantas mágicas, 1975.

Xilografia s/papel, $36.8 \times 25.2, \mathrm{col}$. MAC-USP. tores.

Em suma, pode-se adotar uma postura reformista ou uma postura radical diante dessas questões. Podem-se aceitar os termos em que é posta a alternativa e pensar que simplesmente o mercado é imperfeito e deveria ser estendido para colocar preços naquilo que até hoje era considerado, seja patrimônio comum da humanidade, sejam externalidades. Sob essa perspectiva, a resposta mais simples - a que a CDB adotou - é internalizar tais externalidades da forma mais equitativa possível. A troca de bioprospecção por tecnologia é provavelmente o mais popular desses instrumen- 
tos, como fica evidente na CDB e nas iniciativas da ICBG. Repousa na premissa de que a erosão genética pode ser erradicada, dados os incentivos adequados. Como mostrou Arturo Escobar (1994) em uma excelente análise, foram movimentos sociais do Sul, e particularmente da Ásia do Sudeste (Malásia, Índia), que questionaram os fundamentos últimos da situação atual, a vinculação da erosão da diversidade biológica com a Revolução Verde que favoreceu a monocultura em detrimento da policultura, com o modelo de desenvolvimento que estimulou a criação de gado nas florestas tropicais, financiou estradas e hidroelétricas. E que com isso destruiu formas de sociabilidade e de relação com as florestas. Esses movimentos sociais, representados sobretudo pelo Third World Network e por pessoas como Vandana Shiva (1997) e Gurdial Nijar (1994; 1998), associam portanto erosão social e erosão genética

O TRIPS, como vimos, permite algumas exceções e abre a possibilidade de países estabelecerem um sistema sui generis para a proteção de plantas. Se essa brecha pode ou não ser explorada, depende evidentemente da relação de forças e da mobilização política nos vários países (Grain, 1997; Nijar, 1998).

\section{Uma nota sobre o caráter do saber local}

Vou falar agora, já que sou antropóloga e não jurista, do caráter do saber local. Digo saber local porque, a meu ver, embora a expressão englobe a de saber tradicional ou de saber indigena, ela se presta menos a confusões. A escolha dos termos não é fortuita. Saber local, como aliás qualquer saber, refere-se a um produto histórico que se reconstrói e se modifica, e não a um patrimônio intelectual imutável, que se transmite de geração a geração. Nesse sentido, aliás, não cabem as objeções feitas à aplicação de Direitos de Propriedade Intelectual a conhecimentos tradicionais com o argumento de que, por definição, conhecimentos tradicionais não têm a característica da novidade. Se assim fosse, o problema estaria na erosão do saber, e à maneira dos salvamentos arqueológicos, ou mesmo do ambicioso programa de censo da biodiversidade proposto pelo biólogo Janzen e cujos princípios foram publicados em 1995 pela UNEP (Programa Ambiental das Nações Unidas), dever-se-ia proceder sem mais delongas ao inventário do saber humano.

Mas sendo o saber local um processo de investigação e recriação, o problema está antes na erosão das condições de produção desse saber. Pois qual a natureza daquilo que se transmite? Diria que tanto quanto e talvez mais do que informações, é sobretudo uma combinação de pressupostos, 
formas de aprendizado, de pesquisa e de experimentação. Se entendermos o tradicional como essa forma específica de se praticar ciência (e não como conteídos ancestrais específicos), então a palavra tradicional passa a ser equivalente a local.

A apreciação do saber local oscila entre dois extremos igualmente ingênuos: ora se o desvaloriza por completo por oposição à ciência, ora se o exalta como uma fonte de sabedoria última. Num pólo, fala-se com complacência das crendices e abusões de nosso povo; no outro, com reverência, dos segredos detidos pelos nossos indios.

Existe, sim, um saber local, não desprezível mas tampouco infalível e que está hoje no epicentro, como vimos, de um debate da maior importância. Qual é, porém, o caráter desse saber? Já muito se notaram as minúcias das distinções e dos conhecimentos sobre áreas da natureza que são exploradas. Até hoje degladiam-se posições antagônicas com relação a esse tipo de saber. Muito comum é a explicação utilitarista que ressurge periodicamente sob diversos disfarces e avatares, e que desconhece, entre outras coisas, o vasto excedente de conhecimentos que a razão prática não pode explicar. A essa corrente, opõem-se posições, como a de Lévi-Strauss (1962), que afirmam a natureza teórica do conhecimento selvagem: a diferença entre ciência tradicional e ciência de tipo ocidental, que existe e é enfatizada, não residiria nas operações intelectuais envolvidas, mas nos objetos a que se aplicam, conceitos no caso da grande ciência, propriedades sensíveis na ciência selvagem. Ressalto que para Lévi-Strauss a diferença entre esses dois tipos de ciência existe e é enfatizada, contrariamente a posições como a de Shiva (1997) recentemente contestando a distinção entre as duas sob a alegação pós-moderna de que não há base epistemológica para tanto, e de que a ciência reducionista e cartesiana é tão imbuída de juízos de valor quanto a ciência tradicional. Acho que há aqui um curioso deslocamento: antes, negava-se validade aos conhecimentos tradicionais; agora, ao ser reconhecida sua contribuição, nega-se a distinção no modo de fazer ciência. Que a ciência ocidental, tal qual a ciência tradicional seja informada por ideologias, sistemas de representações que a infletem ao mesmo tempo que lhe conferem coerência, ninguém o negará. Que isso as torne equivalentes, mesmo se ambas produzem conhecimentos reais, é outra história e é negar, a meu ver, que são as diferenças de seus pressupostos que as tornam diferentes e portanto valiosas.

Falei de conhecimentos reais, mas há também os erros empíricos: como dar conta deles? Os Shipibo do Ucayali, no Peru, consideram todas as cobras indistintamente venenosas. Os Ka'apor do Maranhão não distinguem a maioria das plantas tóxicas (Balée, 1994:96-97). 
Um tipo de explicação é dada por Balée (1994:96-97) dizendo que, por economia mental, as plantas venenosas (e seus efeitos) são pouco conhecidas e incluídas simplesmente na categoria geral de plantas não-comestíveis. Balée liga essa economia mental à ausência de escrita e ao caráter oral da transmissão de conhecimentos. Basta saber quais as plantas comestíveis que seriam o "termo marcado": acumular ou transmitir conhecimentos sobre plantas que de qualquer forma ninguém nessa sociedade pensaria em comer, seria irrelevante. Mas a premissa é ela própria problemática, pois o que faz com que certas plantas e não outras sejam consideradas comestíveis?

Outro exemplo dessa mesma economia mental dado por Balée é a indistinção entre cobras venenosas e não-venenosas entre povos que não as usam nem as comem. Supor que todas as cobras, indistintamente, são venenosas "economiza energia mental, é uma hipótese relevante e como tal tem mais chance de ser passada à geração seguinte, dada a precariedade da transmissão oral" (Balée, 1994:101).

Esta passagem revela as várias hipóteses subjacentes: a de que a transmissão oral é precária; a de que a relevância é uma qualidade da prática; a de que a mente economiza energia ao subdiferenciar categorias sem função utilitária.

Mas o que faz com que certas categorias não tenham função utilitária? Não são decerto suas qualidades naturais: o próprio Balée cita o fato de os Parakanã não comerem açaí (Euterpe oleracea) e bacaba (Oenocarpus distichus), enquanto vários de seus vizinhos, lingüisticamente aparentados, como os Araweté, os Ka' ápor, os Guajá e os Tembé apreciam, e muito, os frutos dessas palmeiras (Balée, 1994:99). De forma que o argumento fica um tanto tautológico: os Parakanã ignoram o açaí e a bacaba porque não os comem e não os comem porque os querem ignorar.

A meu ver, tal aspecto releva, antes, aquilo que Levi-Strauss havia chamado um droit de suite, que longe de ser incompatível com a postura empiricista, com a curiosidade e a prática experimentais, mostra a interpenetração dos princípios organizadores com a empiria.

De que se trata? De algo semelhante ao que fazem os farmacólogos quando, sabendo que certas plantas têm princípios ativos, se baseiam nesse fato para pesquisar outras espécies da mesma família. Depois da descoberta, por exemplo, das virtudes anticancerígenas de uma aporinácea, as outras aporináceas passaram a ser pesquisadas. Assim também, princípios organizadores, classificatórios, atuam de dois modos: seja estendendo a 
conjuntos completos (que talvez não as possuam) as propriedades de alguns de seus membros - "Todos os bichos classificados como cobras são venenosos" - seja por contraste, atribuindo a uma categoria de seres características que decorrem da posição dessa categoria no sistema.

O saber local produz conhecimentos valiosos que o mercado está apenas começando a reconhecer. Mas ele tem um valor próprio que independe de seus acertos. Este valor está precisamente na sua diferença (e não na sua semelhança, como quer Shiva) de outras formas de fazer ciência. A grande ciência, quando aliada ao poder e dominando o mercado, oprime a ciência local. Um pouco como o que se acusa a Microsoft de fazer: obrigar o usuário a comprar computadores cada vez mais potentes para realizar tarefas elementares e matar empresas que estão produzindo tecnologia mais sofisticada, mas mais simples e realmente inovadoras. Como se, diz McNealy, o presidente da Sun, tivéssemos de instalar uma usina nuclear no porão para termos energia elétrica em casa. Ou mudar de carro quando se constrói uma nova estrada ( Veja 10 jun.1998). Foi isso que produziu a chamada Revolução Verde. À erosão social e à erosão genética de que falei anteriormente, associa-se também a erosão das condições de produção de conhecimento local e dos sistemas de circulação de conhecimento.

O que vem a ser essa erosão das condições de produção de conbecimento local ? É a deterioração das formas sociais, das instituições, que permitem fazer esse tipo de ciência. Vimos que ela é uma ciência viva, que experimenta, inova, pesquisa, não um simples repositório de conhecimentos. É uma ciência que se baseia, entre outras coisas, na vida e na exploração dos recursos dentro de um território: daí a insistência das organizações indígenas em vincular os dispositivos da $\mathrm{CDB}$ ao reconhecimento de suas terras. E é uma ciência assentada na livre circulação. Nesse aspecto assemelha-se à universidade, aliás, que é uma ilha de liberdade do conhecimento em um mar de conhecimento privatizado. Não quero dizer com isso, o que seria um contra-senso, que não existe nas comunidades tradicionais conhecimento especializado, reservado ou esotérico. Há, entre grupos indígenas e tradicionais em geral, carreiras que em muito também se assemelham à carreira acadêmica. No entanto, esse saber, que costuma ser revelado ou transmitido de mestre a discípulo, não se presta a um monopólio de tipo comercial. São bem conhecidos os casos em que os curadores, por sucumbirem à tentação de monopolizar e comercializar seu saber, acabam executados ou exilados pelos membros do grupo. Também existem, e isso é atestado na Amazônia, especializações de grupos que não repousam em qualquer incompetência tecnológica, mas permitem circulação de bens e relações não-belicosas entre grupos diferentes. 
As rotas de comércio do curare, das zarabatanas, dos cachorros, dos raladores de mandioca, da cerâmica, dos adornos assentam-se, em muitos grupos, em uma especialização desse tipo: embora os vários parceiros comerciais conheçam as técnicas necessárias para se auto-abastecerem de cada um desses produtos, preferem no entanto os benefícios e os prazeres da troca. O mesmo se pode dizer das variedades locais de plantas. Quem já viajou pelos rios e igarapés da Amazônia sabe bem que seus companheiros de viagem, principalmente mulheres, estão sempre trocando mudas e sementes ao longo do rio. Essas plantas guardam sua história, sua origem é lembrada, e são muitas vezes semeadas em áreas separadas dos roçados. Cada roçado torna-se assim um mini-jardim botânico.

São essas condições essenciais da produção do saber local que as propostas de diveitos intelectuais coletivos querem preservar. Como? Impedindo por exemplo a monopolização por terceiros de conhecimentos locais. Ou seja, "assegurando o caráter de bens públicos dos conhecimentos locais e sua livre circulação. Se, no entanto, forem desenvolvidos conhecimentos, produtos, inovações, de caráter comercial, para os quais os conhecimentos locais tenham contribuído, deve ser reconhecido esse aporte, por meio de 'royalties' ou co-titularidade" (Nijar, 1994; 1998).

Co-patentear com os grupos tradicionais os produtos dos seus conhecimentos - solução de vários dos projetos do ICBG -, embora valorize sua contribuição, pode implicar paradoxalmente o fim da produção desse conhecimento. Não é à toa que, na nova rodada de propostas do ICBG, se chama a atenção para as condutas potencialmente conflitivas dos grupos tradicionais e dos cientistas, os primeiros agora aliados à política de segredo das indústrias e os últimos interessados na divulgação da pesquisa. São necessários a valorização dos conhecimentos e das variedades de plantas, a co-titularidade, os pagamentos de royalties, mas não são suficientes. É preciso preservar também o caráter público, não-patenteável, do conhecimento e das sementes locais, que é condição de seu florescimento. Em suma, patentear $n \tilde{a} o$, retribuir o aporte e compartilhar os benefícios, sim.

\section{À guisa de conclusão}

Os Estados com tecnologia e os Estados ricos em biodiversidade não têm interesses coincidentes, e os primeiros têm grande poder de pressão econômica sobre os últimos. O resultado é a tendência à depreciação da biodiversidade e dos conhecimentos associados. Quando os EUA vincularam sanções comerciais ao desrespeito dos Direitos de Propriedade Intelectual na Rodada Uruguai, apregoaram que estavam perdendo US\$ 202 
milhões em defensivos agrícolas e US \$ 2,5 bilhões em produtos farmacêuticos. Se, no entanto, se levar em conta a contribuição do Terceiro Mundo, credores e devedores se invertem. Os EUA estariam devendo US\$ 302 milhões em agricultura e US\$ 5 bilhões em produtos farmacêuticos (4). Ou seja, os EUA devem um saldo de US\$ 2,7 bilhões ao Terceiro Mundo.

Para que os Estados nacionais não rifem seu cabedal de biodiversidade e de conhecimentos associados e consigam a adesão de suas populações tradicionais para a valorização do patrimônio, caber-lhes-iam pelo menos três medidas imediatas: a de protegerem, mediante um sistema legal, os conhecimentos locais; a de salvaguardarem a livre circulação de sementes, cultivares e formas de vida em geral opondo-se ao seu patenteamento; a de estabelecerem as regras de negociação mínimas para que comunidades locais não possam ser lesadas.

\section{Notas}

1 Para uma excelente discussão desses assuntos, vide Juliana Santilli, 1997.

2 Já se observou, no entanto, que a remuneração dos grupos é muito diferente conforme os casos. Chamou particularmente a atenção o fato de o Parque Nacional de Yellowstone ter obtido $10 \%$ de royalties sobre as vendas em contrato com a Diversa, pela prospecção em regime de não-exclusividade de certos microorganismos presentes em fontes termais. Nesse caso, o governo dos EUA atua como fornecedor remunerado. Em contratos em que, ao contrário, o governo dos EUA é o co-financiador, como nos do ICBG, as ofertas para os grupos de origem variaram desde $0,25 \%$ de royalties sobre os lucros no caso do Peru (que depois renegociou esse acordo, com números que não foram divulgados) até 2 a 3\% no caso do Surinam. Embora os dados não sejam oficiais, estima-se que os royalties que a Merck ofereceu à InBio da Costa Rica pelos direitos sobre recursos genéticos foram de 4 a $5 \%$ das vendas futuras. Esses exemplos evidenciam a flagrante diferença na força de barganha entre os contratantes (RAFI, 1997).

3 Resta saber ainda se esse usufruto exclusivo não acaba encobrindo um monopólio que atrapalha em vez de estimular a inovação.

4 Os dados, citados por Vandana Shiva, foram calculados pelo RAFI, Rural Advancement Foundation International, uma ONG sediada no Canadá. 
Referências bibliográficas

BALÉE, William. Footprints in the forest. Columbia University Press, 1994.

CUNNINGHAM, A.B. Ethics, ethnobiological research and biodiversity. WWF paper, 44, 1993.

ESCOBAR, Arturo. Biodiversidad, naturaleza y cultura: localidad y globalidad en las estrategias de conservación, Bogotá, ms, 1994.

GRAIN (ed.). The international context of the 'sui generis' rights debate, 1997.

KLOPPENBURG JR., Jack. No hunting! Biodiversity, indigenous rights, and scientific poaching. Cultural Survival Quarterly, 1991.

KLOPPENBURG JR., Jack \& KLEINMAN, Daniel L. The plant germplasm controversy. Bioscience, vol. 37, n. 3, p. 190-198, 1987.

LÉVI-STRAUSS, Claude. La pensée sauvage. Paris, Plon, 1962.

MAYS, Thomas D.; MAZAN, Kate; ASEBEY, Edgar; BOYD, Michael \& GRAGG, Goron. Quid pro quo: alternatives for equity and conservation. In St.Brush \& D.Stabinski (eds.). Valuing local knowledge. Indigenous peoples and intellectual property rights. Island Press, 1996, p. 259-280.

NIJAR, Gurdial Singh. Towards a legal framework for protecting biological diversity and community intellectual rights: a Third World perspective. Third World Network Discussion Paper, 27 p. and appendixes, ms, 1994.

. North undermining implementation of biodiversity convention, 1988, http://www.twnside.org.sg/south/twn/title/nij-cn.htm.

RAFI. Biopiracy update. The inequitable sharing of benefits. RAFI Communique, Sept./Oct. 1997, http://www.rafi.org/communique/19975.html.

ROSENTHAL, Joshua. Equitable sharing of biodiversity benefits: agreements on genetic resources. OECD International Conference on Biodiversity Incentive Measures. Cairns, Australia, March 25-28, 1996.

SANTILLI, Juliana. A proteção aos direitos intelectuais coletivos das comunidades indígenas brasileiras. Revista do Centro de Estudos Judiciários, v. 1, n. 3, p. 46-53, 1997.

SHIVA, Vandana. The politics of knowledge at the CBD, http:// www.twnside.org.sg/souths/twn/title/cbd-cn.htm.

UNCTAD/WIPO. The role of the patent system in the transfer of technology to developing countries. New York, United Nations, New York 1975. 
RESUMO - OS CONHECIMENTOS e o papel de populações tradicionais com relação a seus recursos genéticos são hoje reconhecidos na Convenção da Diversidade Biológica (CDB). O acordo TRIPS e a CDB estão levando o Brasil e muitos outros países signatários a mudarem sua legislação sobre direitos intelectuais e sobre o acesso a recursos genéticos e conhecimentos. Diante disso, colocam-se alternativas que são discutidas neste artigo. Deve-se estender o sistema de direitos de propriedade intelectual às populações tradicionais? Ou melhor, devem-se manter o seu saber no domínio público mas assegurando-lhes participação em eventuais benefícios comerciais derivados de seus conhecimentos? E qual a natureza desse saber local?

ABSTRACT - THE CONVENTION for Biological Diversity (CDB) has acknowledged the importance of traditional knowledge and stewardship of genetic ressources. The TRIPS agreement and the CBD are leading Brazil and other countries to change their legislation on intellectual rights and on access to genetic ressources and associated knowledge. Should one then extend the intellectual property system to cover local and indigenous knowledge? Or should one rather maintain it in the public domain and assure that local people participate in the possible benefits of commercial products derived from it? And then, what is the nature of local knowledge?

Manuela Carneiro da Cunba é professora do Departamento de Antropologia da Faculdade de Filosofia, Letras e Ciências Humanas da Universidade de São Paulo. 